\title{
Oat Extract Avenanthramide-C Reverses Hippocampal Long-Term Potentiation Decline in Tg2576 Mice
}

\author{
Yu-Young Lee ${ }^{1, *,+}$, Ming Wang ${ }^{2,+}$, Yurim Son ${ }^{1}$, Eun-Ju Yang ${ }^{3}$, Moon-Seok Kang ${ }^{1}$, Hyun-Joo Kim ${ }^{1}$, \\ Hyung-Seok Kim ${ }^{4,5, *}$ and Jihoon Jo ${ }^{2, *}$
}

1 Department of Central Area, National Institute of Crop Science, Rural Development Administration, Suwon 16429, Korea; yurim1023@gmail.com (Y.S.); gr27@korea.kr (M.-S.K.); tlrtod@korea.kr (H.-J.K.)

2 Department of Biomedical Sciences, Chonnam National University Medical School, Gwangju 501-757, Korea; Ming322@jnu.ac.kr

3 Research Institute of Pharmaceutical Sciences, College of Pharmacy, Kyungpook National University, 80 Daehak-ro, Daegu 41566, Korea; ejy125@gmail.com

4 Department of Forensic Medicine, Chonnam National University Medical School, Gwangju 501-757, Korea

5 Center for Creative Biomedical Scientists, Chonnam National University Medical School, Gwangju 501-757, Korea

* Correspondence: leeyy260@korea.kr (Y.-Y.L.); veritas@chonnam.ac.kr (H.-S.K.); Jihoon.Jo@jnu.ac.kr (J.J.)

+ These authors contributed equally to this work.

check for updates

Citation: Lee, Y.-Y.; Wang, M.; Son, Y.; Yang, E.-J.; Kang, M.-S.; Kim, H.-J.; Kim, H.-S.; Jo, J. Oat Extract Avenanthramide-C Reverses Hippocampal Long-Term Potentiation Decline in Tg2576 Mice. Molecules 2021, 26, 6105. https:// doi.org/10.3390/molecules26206105

Academic Editor:

José Marco-Contelles

Received: 6 September 2021

Accepted: 2 October 2021

Published: 10 October 2021

Publisher's Note: MDPI stays neutral with regard to jurisdictional claims in published maps and institutional affiliations.

Copyright: (c) 2021 by the authors. Licensee MDPI, Basel, Switzerland. This article is an open access article distributed under the terms and conditions of the Creative Commons Attribution (CC BY) license (https:// creativecommons.org/licenses/by/ $4.0 /)$.

\begin{abstract}
Memory deterioration in Alzheimer's disease (AD) is thought to be underpinned by aberrant amyloid $\beta(A \beta)$ accumulation, which contributes to synaptic plasticity impairment. Avenanthramide-C (Avn-C), a polyphenol compound found predominantly in oats, has a range of biological properties. Herein, we performed methanolic extraction of the Avns-rich fraction (Fr. 2) from germinated oats using column chromatography, and examined the effects of Avn-C on synaptic correlates of memory in a mouse model of AD. Avn-C was identified in Fr. 2 based on ${ }^{1} \mathrm{H}-\mathrm{NMR}$ analysis. Electrophysiological recordings were performed to examine the effects of Avn-C on the hippocampal long-term potentiation (LTP) in a Tg2576 mouse model of AD. Avn-C from germinated oats restored impaired LTP in Tg2576 mouse hippocampal slices. Furthermore, Avn-C-facilitated LTP was associated with changes in the protein levels of phospho-glycogen synthase kinase-3 $\beta$ (p-GSK3 $\beta$-S9) and cleaved caspase 3, which are involved in A $\beta$-induced synaptic impairment. Our findings suggest that the Avn-C extract from germinated oats may be beneficial for AD-related synaptic plasticity impairment and memory decline.
\end{abstract}

Keywords: memory; Alzheimer's disease; avenanthramide-C; polyphenol; oats; hippocampal synaptic plasticity; amyloid $\beta$

\section{Introduction}

Alzheimer's disease (AD) is an irreversible, progressive neurodegenerative disease that is associated with deficits in cognitive function and memory loss [1]. Progressive memory impairment in AD is thought to be encoded by synaptic degeneration [2]. Several hypotheses that have been put forward for AD pathogenesis, the amyloid hypothesis is one of the factors, which give the concept that excessive amyloid beta $(A \beta)$ levels predominantly cause the origin and progression of the nervous system dysfunction and synaptic pathology [3]. The best understood AD pathogenesis in the central nervous system (CNS) could be concluded in a loss of plasticity [4]. As such, measurement of the synaptic plasticity is considered a useful indicator in the evaluation of AD pathophysiology. Synaptic plasticity refers to the long-lasting enhancement of synaptic efficacy induced by trains of electrical stimuli. Several forms of synaptic plasticity have been described in the mammalian central nervous system (CNS). Long-term potentiation (LTP) and other forms of synaptic plasticity are typically regarded as the core cellular substrates underlying learning and memory $[5,6]$. Electrophysiological recordings of LTP in the mouse hippocampal CA1 region are widely 
used to investigate synaptic efficacy under normal and pathological conditions [7-9]. Developing the therapeutic candidates that against the $A \beta$ toxicity would be beneficial for memory retrieval in $\mathrm{AD}$; one study recently reported that Aducanumab, which is approved by the FDA, could reduce $\mathrm{A} \beta$ plaque in $\mathrm{AD}$ patients' brain [10]. Although numerous research groups have targeted the pathogenesis of $\mathrm{AD}$, few of therapeutic agents have been provided. However, natural compounds, due to their antioxidants and anti-inflammatory properties, have been recently documented as promising candidates for the prevention and treatment of AD [11-13].

Oats (Avena sativa L.) are a healthy and nutritious food containing high concentrations of well-balanced protein, soluble fiber, and energy, as well as a variety of vitamins and minerals $[14,15]$. The consumption of oats has been reported to provide various benefits such as suppressing host cholesterol, reducing the risk of cardiovascular disease, alleviating diabetes symptoms [16], and preventing obesity [17]. $\beta$-glucan is the primary component of oats that is considered to underpin many of these health benefits; however, other constituents of oats may also have beneficial effects. Oats possess a high antioxidant capacity due to the presence of tocopherols, tocotrienols, phytic acid, flavonoids, and phenolic compounds, including avenanthramides (Avns) [18].

Avns comprise three major isoforms, namely, Avn-A, Avn-B, and Avn-C, which belong to the esters of 5-hydoroxyanthranilic acid with $p$-coumaric (Bp), ferulic (Bf), and caffeic acid (Bc), respectively [19]. The antioxidant activity of Avns is 10-30 times greater than that of other typical cereal components, such as gentisic acid, phydroxybenzoic acid, protocatechuic acid, syringic acid, ferulic acid, and vanillin [20-23]. Additionally, the beneficial anti-inflammatory, anti-hypertensive, and anti-atherogenic effects of Avns are well-documented $[24,25]$. Among the Avns, the Avn-C constituent in oats is two-fold higher than that of Avn-A and Avn-B [26]. The antioxidant capacity of Avn-C has been reported to closely resemble that of the standard synthetic antioxidant, butylated hydroxytoluene (BHT), in $\beta$-carotene. Moreover, Avn-C has a higher bioactivity compared with 6-hydroxy2,5,7,8-tetramethylchromane-2-carboxylic acid (Trolox) in DPPH [27].

Recent evidence suggests that synthetic Avn-C exerts a protective role on synaptic impairment in AD pathology [28]. Given the potential applicability of harnessing this treatment for $\mathrm{AD}$, in this study, we performed methanolic isolation of Avn-C from sprouted oats to evaluate the effects of purified Avn-C on synaptic plasticity in a mouse model of AD. Our findings suggest that Avn-C reverses hippocampal LTP decline, highlighting its therapeutic potential as a treatment for memory impairment in AD.

\section{Results and Discussion}

\subsection{Avn Content in Different Oat Cultivars}

The Avn content in nine Korean cultivars of oats is presented in Table 1. The total Avn content ranged from 2.9-188.7. Oat samples from DY contained the highest levels of all types of Avns (Avn-C, Avn-A, and Avn-B), whereas SH seeds contained the lowest levels of total Avns. Among the oat cultivars, Avn content was higher in DY, JM, SY, SE, and CY from naked oats. However, the total Avn content was lower in DH, JP, HS, and SH from hulled oats, in agreement with previous reports [29]. Avn-C content varied notably among the different oat cultivars, with the highest value observed in DY $(86.9 \pm 24.1 \mu \mathrm{g} / \mathrm{g}, p<0.01)$. In agreement with our findings, a previous study reported that the mean Avn content was $65.7 \mathrm{mg} / \mathrm{kg}$ and $62.2 \mathrm{mg} / \mathrm{kg}$ in Belle and Gem, respectively, which was higher than that in Dane $(37.1 \mathrm{mg} / \mathrm{kg})$, and that the Avn quantity in oats was influenced by genotype and environmental factors [30]. Indeed, Switzerland produces oats with a lower Avn content compared with Canada [20]. 
Table 1. Comparison of Avn contents in oat cultivars ( $\mu \mathrm{g} / \mathrm{g})$.

\begin{tabular}{|c|c|c|c|c|c|c|}
\hline Type & Cultivars & Abbr. & Avn-C & Avn-A & Avn-B & Total Avn \\
\hline \multirow{5}{*}{ Naked } & Seonyang & SE & $11.7 \pm 2.5^{b}$ & $13.7 \pm 3.5^{b}$ & $13.4 \pm 3.9^{b}$ & $38.9 \pm 8.8^{b}$ \\
\hline & Daeyang & DY & $86.9 \pm 24.1^{a}$ & $52.7 \pm 16.7^{a}$ & $49.1 \pm 24.3^{\mathrm{a}}$ & $188.7 \pm 85.1^{\mathrm{a}}$ \\
\hline & Choyang & $\mathrm{CY}$ & $7.8 \pm 1.7^{\mathrm{b}}$ & $8.6 \pm 2.4^{b}$ & $10.5 \pm 6.1^{\mathrm{b}}$ & $27.0 \pm 10^{b}$ \\
\hline & Suyang & SY & $15.9 \pm 0.7^{b}$ & $14.3 \pm 2.7^{b}$ & $21.1 \pm 9.5^{b}$ & $51.3 \pm 11.6^{b}$ \\
\hline & Jungmo2005 & JM & $22.9 \pm 6.8^{b}$ & $26.4 \pm 8.3^{a b}$ & $18 \pm 3.1^{b}$ & $67.4 \pm 18.2^{b}$ \\
\hline \multirow{5}{*}{ Hulled } & Samhan & $\mathrm{SH}$ & $1.6 \pm 0.2^{c}$ & $0.0 \pm 0.1^{\mathrm{c}}$ & $1.3 \pm 0.1^{\mathrm{c}}$ & $2.9 \pm 0.4^{\mathrm{c}}$ \\
\hline & Donghan & $\mathrm{DH}$ & $3.4 \pm 1.1^{\mathrm{c}}$ & $3.7 \pm 1.0^{\mathrm{c}}$ & $7.5 \pm 1.9^{b c}$ & $14.7 \pm 3.9^{c}$ \\
\hline & Highspeed & HS & $3.3 \pm 0.1^{c}$ & $2.4 \pm 0.1^{\mathrm{c}}$ & $3.6 \pm 0.1^{\mathrm{c}}$ & $9.3 \pm 0.3^{c}$ \\
\hline & Jopung & $\mathrm{JP}$ & $3.6 \pm 0.1^{\mathrm{c}}$ & $3.0 \pm 0.0^{c}$ & $3.5 \pm 0.1^{\mathrm{c}}$ & $10.1 \pm 0.2^{\mathrm{c}}$ \\
\hline & & & & $* *$ & * & $* *$ \\
\hline
\end{tabular}

Data represent the means of three replicates \pm S.E.M. ${ }^{\mathrm{a}, \mathrm{b}, \mathrm{c}}$ Means values in the same raw with different superscripts are significantly different at ${ }^{*} p<0.05,{ }^{* *} p<0.01$ according to Ducan's multiple range test. Avn-C, avenanthramide C; Avn-A, avenanthramide A; Avn-B, avenanthramide B; Abbr., abbreviation.

Germinated oat samples from DY were selected for Avn extraction. The mean Avn content decreased slightly after germination for $24 \mathrm{~h}$, but increased significantly after germination for $48 \mathrm{~h}$ and $72 \mathrm{~h}$, respectively $(p<0.01)$ (Table 2$)$. The Avn-C and total Avn contents in germinated oats were approximately 2.5 -fold higher than those in raw oats. The total phenol content and antioxidant activity in the procedure-rich fraction are presented in Table 3. These findings are consistent with those of a previous report that the Avn content of germinated oats is higher in Vista, Gem, and Dane oat cultivars than in raw oats [31].

Table 2. Changes in Avn content in germinated oats ( $\mu \mathrm{g} / \mathrm{g})$.

\begin{tabular}{ccccc}
\hline Germination Time (h) & Avn-C & Avn-A & Avn-B & Total Avns \\
\hline 0 & $84.3 \pm 3.1^{\mathrm{b}}$ & $64.1 \pm 2.3^{\mathrm{a}}$ & $58.1 \pm 2.2^{\mathrm{a}}$ & $206.5 \pm 7.6^{\mathrm{a}}$ \\
24 & $75.5 \pm 1.7^{\mathrm{c}}$ & $49.9 \pm 0.6^{\mathrm{a}}$ & $46.4 \pm 1.2^{\mathrm{a}}$ & $171.9 \pm 3.4^{\mathrm{a}}$ \\
48 & $216.0 \pm 1.9^{\mathrm{a}}$ & $165.2 \pm 2.2^{\mathrm{a}}$ & $115.5 \pm 1.4^{\mathrm{a}}$ & $496.7 \pm 4.0^{\mathrm{a}}$ \\
72 & $218.8 \pm 4.0^{\mathrm{a}}$ & $173.2 \pm 2.9^{\mathrm{a}}$ & $129.5 \pm 4.2^{\mathrm{a}}$ & $521.5 \pm 11.0^{\mathrm{a}}$ \\
\hline
\end{tabular}

Data represent the means of three replicates \pm S.E.M. ${ }^{\text {a,b,c }}$ Means values in the same raw with different superscripts are significantly different at $p<0.05$ according to Ducan's multiple range test. Avn-C, avenanthramide C; Avn-A, avenanthramide A; Avn-B, avenanthramide B Avn, av-enanthramide.

Table 3. Changes in the antioxidant activity of rich fraction extracts.

\begin{tabular}{cccc}
\hline Extract (1 g) & $\begin{array}{c}\text { DPPH } \\
\text { (mg TE/100 g of Sample) }\end{array}$ & $\begin{array}{c}\text { ABTS } \\
\text { (mg TE/100 g of Sample) }\end{array}$ & $\begin{array}{c}\text { Polyphenol } \\
\text { (mg GAE/g of Extract) }\end{array}$ \\
\hline Germinated grain & $11.02 \pm 1.23^{\mathrm{b}}$ & $30.76 \pm 2.17^{\mathrm{b}}$ & $30.49 \pm 2.39^{\mathrm{b}}$ \\
MN & $9.05 \pm 0.32^{\mathrm{c}}$ & $25.35 \pm 0.29^{\mathrm{c}}$ & $27.40 \pm 0.60^{\mathrm{c}}$ \\
Fr. 2 & $29.77 \pm 0.94^{\mathrm{a}}$ & $37.11 \pm 0.21^{\mathrm{a}}$ & $44.01 \pm 1.32^{\mathrm{a}}$ \\
\hline
\end{tabular}

The effects of fraction extract on antioxidant activity were determined using DPPH, ABTS, and Folin-Ciocalteau assays. The data are presented as $\mathrm{mg}$ of TE per $100 \mathrm{~g}$ (DPPH and ABTS) of extract and $\mathrm{mg}$ of GAE per $\mathrm{g}$ of the extract. The data are presented as mean \pm S.E.M. Values with different superscripts are significantly different at $p<0.05$ based on one-way ANOVA and Ducan's multiple range test. TE, Trolox equivalent; GAE, Gallic acid equivalent; MN, methanolic extract; Fr. 2, Avn-C-rich fraction.

\subsection{Identification of Avn-C Content in Fr. 2}

Methanolic extraction of the Avn-rich fraction (Fr. 2) from germinated oats was performed using column chromatography. Avn-C was identified in Fr. 2 based on ${ }^{1} \mathrm{H}-\mathrm{NMR}$ analysis. Figure 1 illustrates the Avn-C extraction procedure. In total, $31 \mathrm{mg} / \mathrm{g}$ of total Avns and $0.52 \pm 0.02 \%$ of $\beta$-glucan were obtained from Fr. 2. Fr. 2 contained high levels of Avn-C (99.9\% of total Avns), but only low levels of Avn-A and Avn-B were detected (Table 4). The Avn-C content of Fr. 2 was 16-fold higher than that of raw oats. The $\beta$-glucan content of Fr. 2-2 was approximately five-fold lower than that of Fr. 2. 


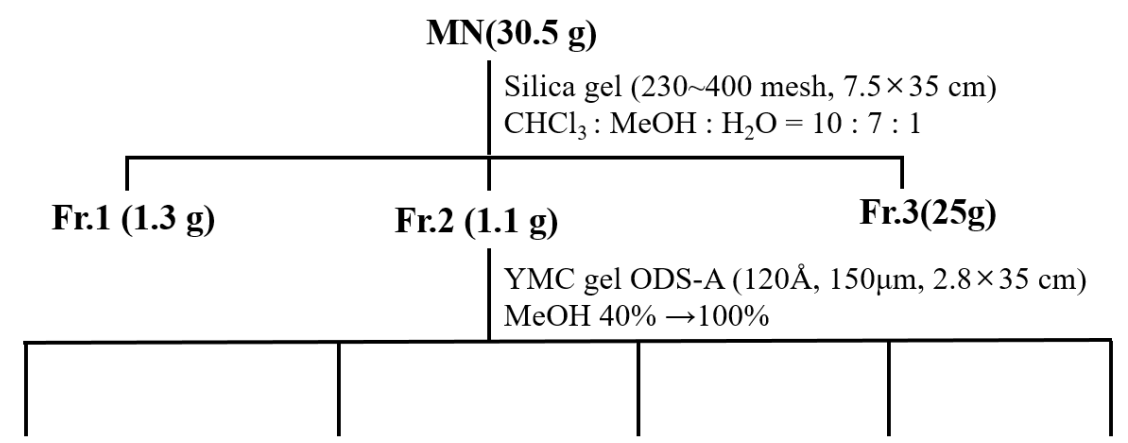

Fr.2-1 (850mg) Fr.2-2 (97mg) Fr.2-3 (50mg) Fr.2-4(30mg) Fr.2-5(100mg)

\author{
HPLC(C18, 250x10mm) \\ Flow rate : $3 \mathrm{~mL} / \mathrm{min}$ \\ $\mathrm{MeOH}: \mathrm{H}_{2} \mathrm{O}=4: 6$ \\ Detection : UV $254 \mathrm{~nm}, 280 \mathrm{~nm}, 365 \mathrm{~nm}$
}

Avenanthramide C (2.1mg)

Figure 1. Procedure of Avn-C extraction. MN, methanolic extract; HPLC, high-performance liquid chromatography. Fr. 2, Avn-C-rich fraction; Avn-C, avenanthramide C; Avn-A, avenanthramide A; Avn-B, avenanthramide B.

Table 4. Avn-C contents in Fr. 2 (mg/g).

\begin{tabular}{|c|c|c|c|c|c|c|c|}
\hline Extract & Weight (g) & Avn-C & Avn-A & Avn-B & Total Avns & Yield (\%) & $\begin{array}{c}\beta \text {-glucan \% } \\
(\mathrm{g} / 100 \mathrm{~g})\end{array}$ \\
\hline Fr. 2 & 1.1 & 31.11 & 0.01 & 0.00 & 31.12 & 0.2 & $0.52 \pm 0.02$ \\
\hline
\end{tabular}

Fr. 2, Avn-C-rich fraction; Avn-C, avenanthramide C; Avn-A, avenanthramide A; Avn-B, avenanthramide B.

\title{
2.3. Isolation and Purification of Avn-C
}

The purity of isolated compound 1 from Fr. 2 was evaluated by spectrum (Figures 2 and 3) and was confirmed as Avn-C by ${ }^{1} \mathrm{H}-\mathrm{NMR}$ analysis (Figure 4).

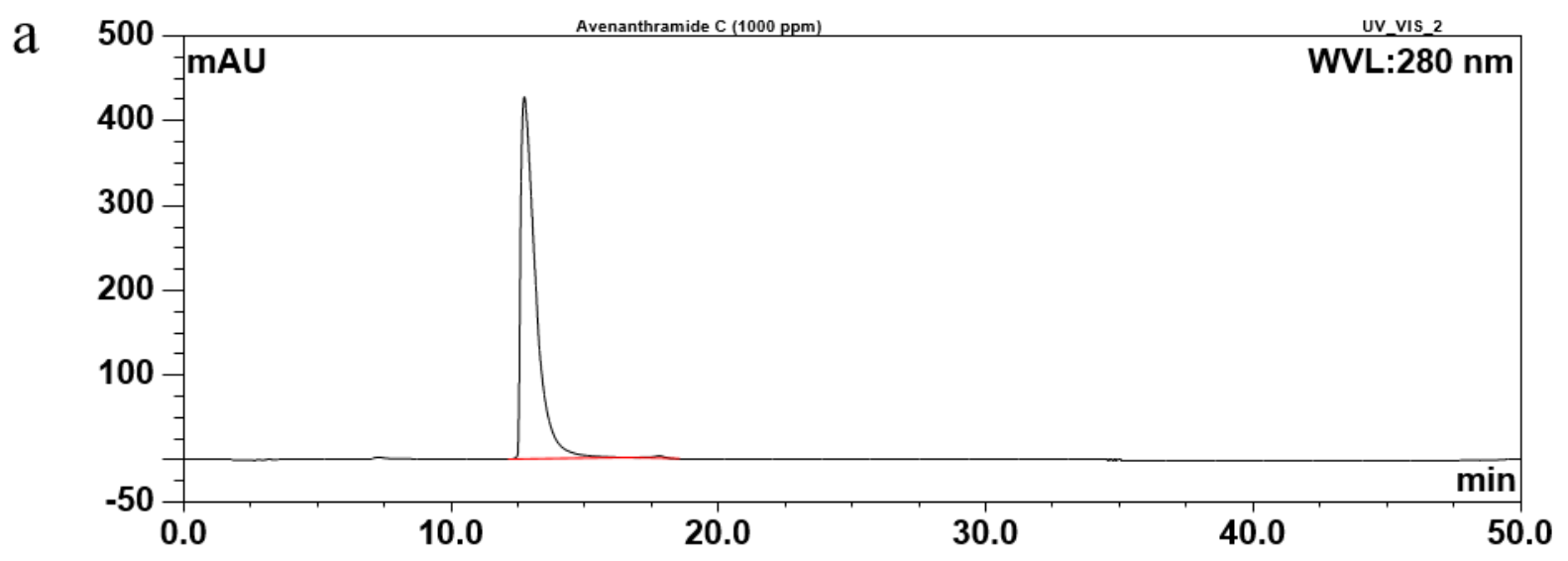

Figure 2. Cont. 

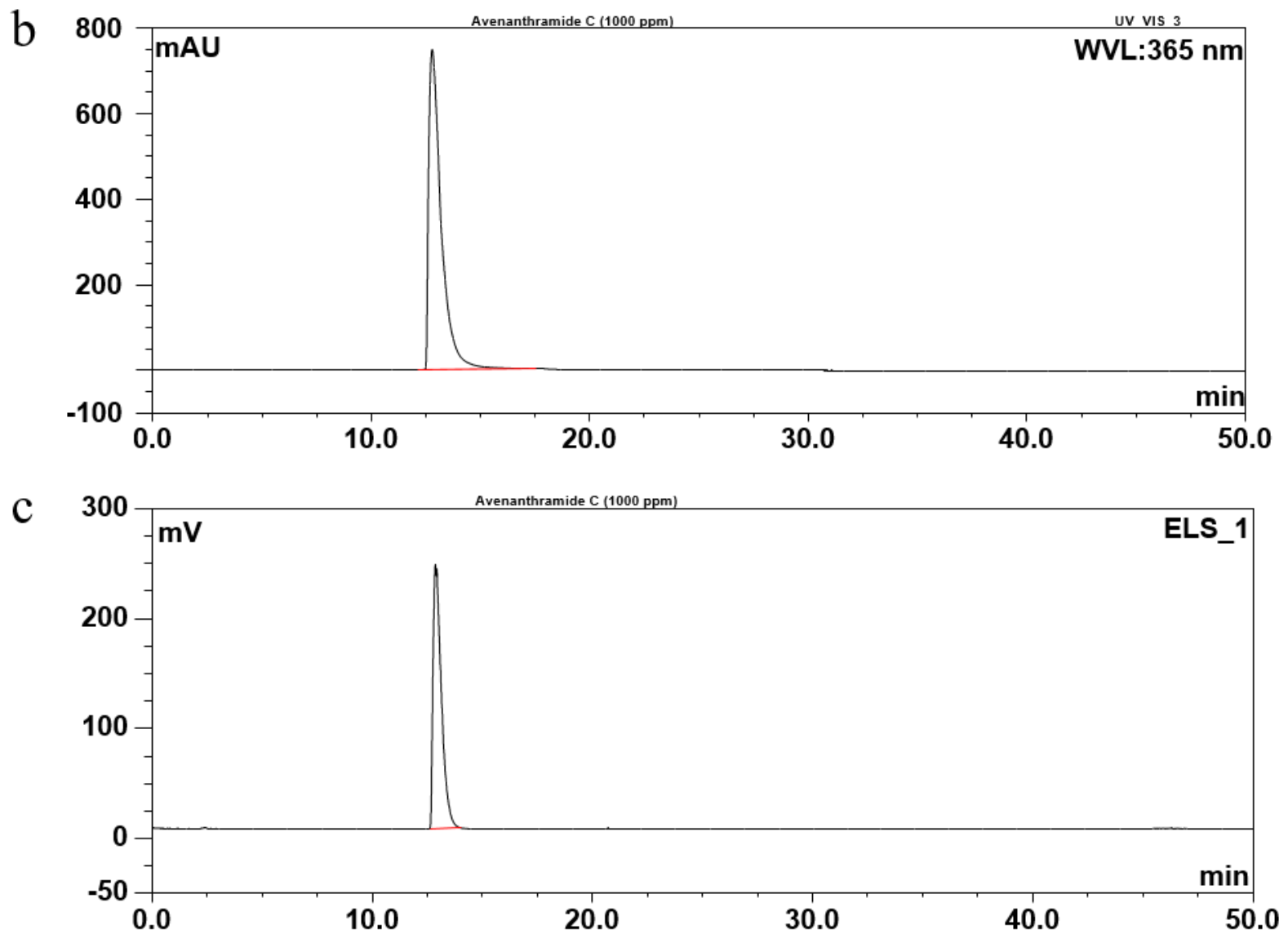

Figure 2. HPLC chromatograms of Avn-C isolated from Fr. 2. Avn-C was detected by UV $254 \mathrm{~nm}(\mathbf{a})$, UV 365 nm (b), and $\operatorname{ELSD}(\mathbf{c})$.

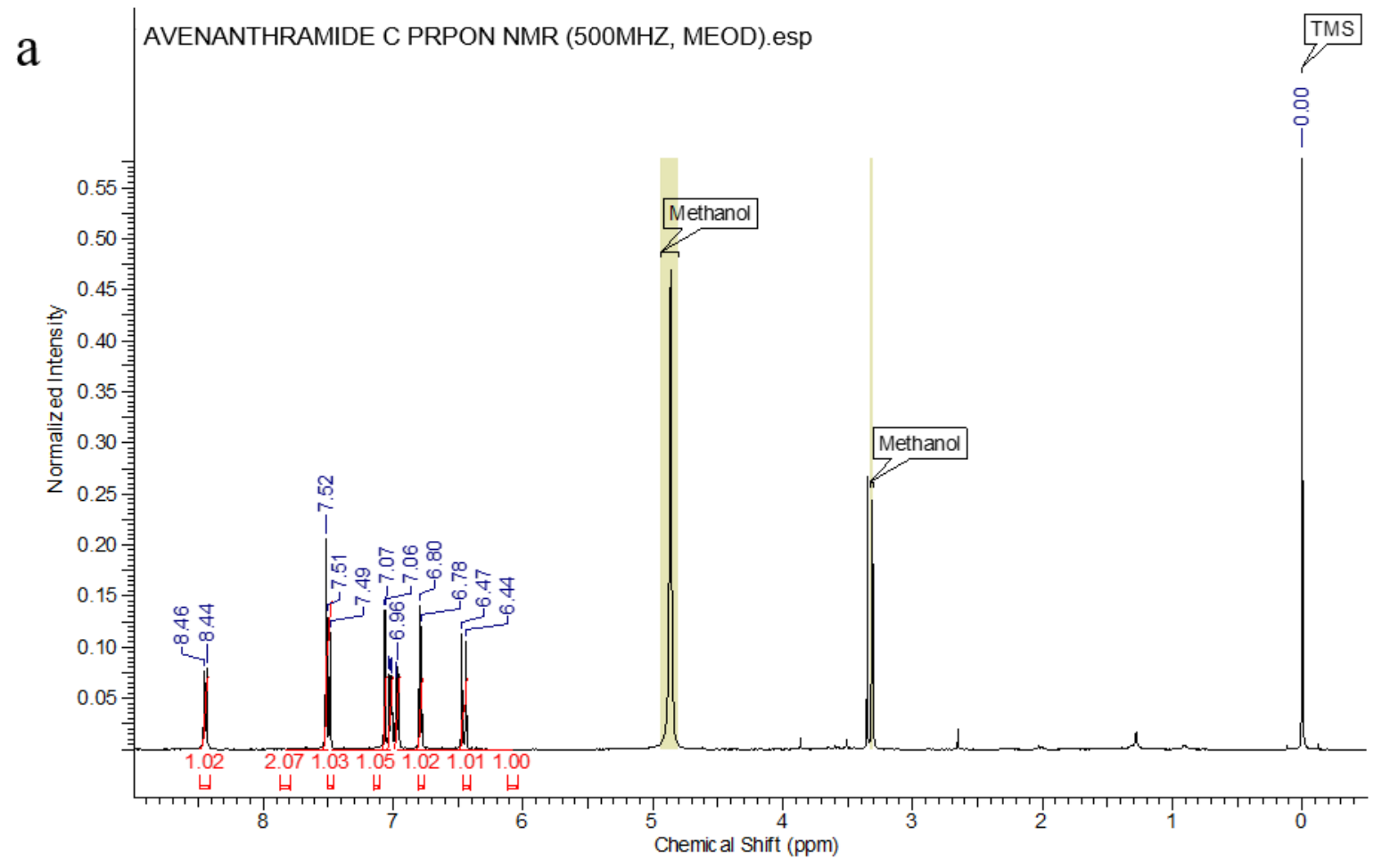

Figure 3. Cont. 


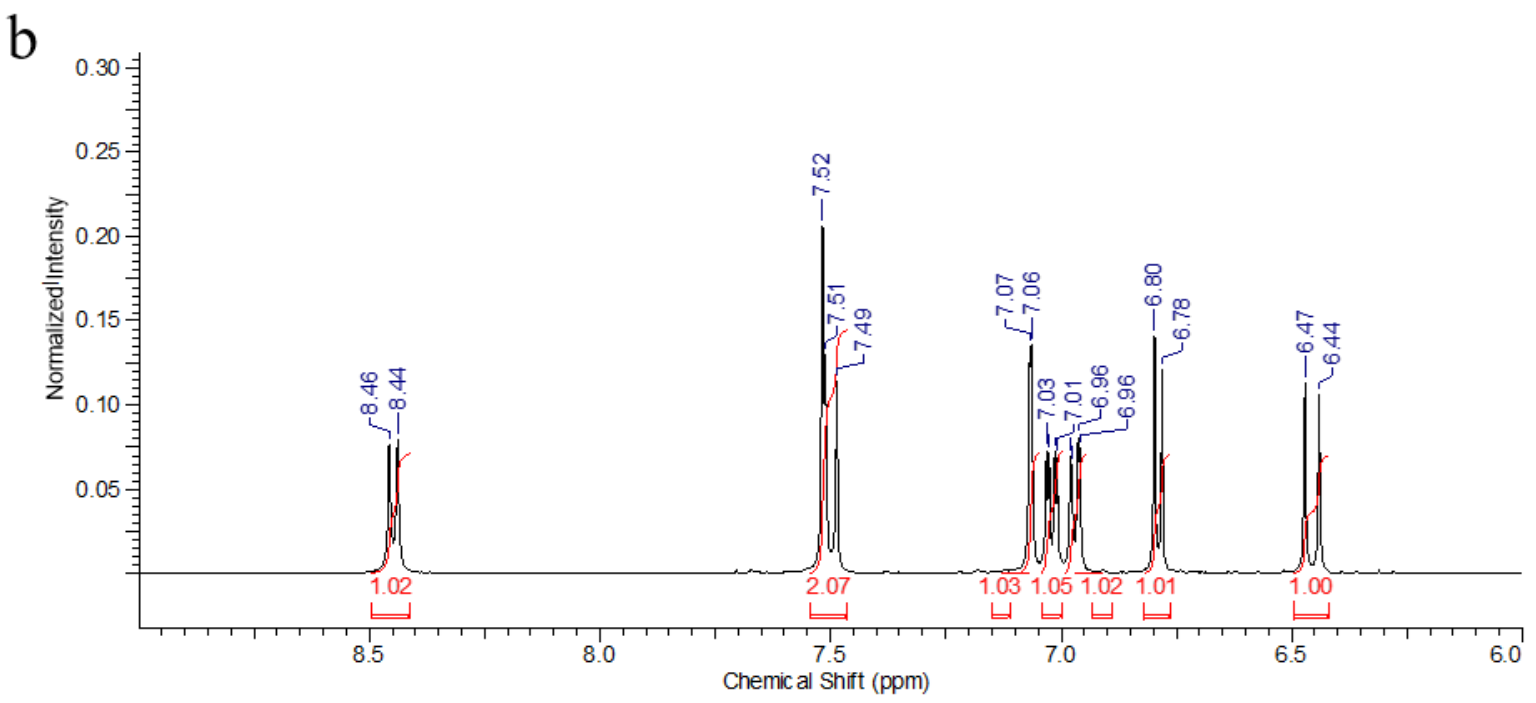

Figure 3. ${ }^{1} \mathrm{H}$ NMR spectra of Avn-C (MeOH-d4). (a) The whole spectrum. (b) The magnified spectrum from 9.0 to 6.0 ppm.<smiles>O=C(/C=C/c1ccc(O)c(O)c1)Nc1ccc(O)cc1C(=O)O</smiles>

Figure 4. The chemical structure of compound 1 (Avn-C) isolated from germinated oats.

Compound 1: light green powder; ${ }^{1} \mathrm{H}-\mathrm{NMR}\left(500 \mathrm{MHz}, \mathrm{MeOH}-d_{4}\right): 88.45(1 \mathrm{H}, \mathrm{d}$, $J=9.0 \mathrm{~Hz}, \mathrm{H}-3), 7.52(1 \mathrm{H}, \mathrm{d}, J=3.2 \mathrm{~Hz}, \mathrm{H}-6), 7.50\left(1 \mathrm{H}, \mathrm{d}, J=15.6 \mathrm{~Hz}, \mathrm{H}-7^{\prime}\right), 7.07(1 \mathrm{H}, \mathrm{d}$, $\left.J=1.7 \mathrm{~Hz}, \mathrm{H}-2^{\prime}\right), 7.02(1 \mathrm{H}, \mathrm{dd}, J=9.0$ and $3.2 \mathrm{~Hz}, \mathrm{H}-4), 6.97\left(1 \mathrm{H}, \mathrm{dd}, J=8.2\right.$ and $\left.1.7 \mathrm{~Hz}, \mathrm{H}-6^{\prime}\right)$, $6.79\left(1 \mathrm{H}, \mathrm{d}, J=8.2 \mathrm{~Hz}, \mathrm{H}-5^{\prime}\right)$, and $6.46\left(1 \mathrm{H}, \mathrm{d}, J=15.6 \mathrm{~Hz}, \mathrm{H}-8^{\prime}\right)$ (Figure 3). From these data, compound 1 was postulated as Avn-C and this was finally confirmed by a comparison of these results from the ${ }^{1} \mathrm{H}-\mathrm{NMR}$ analysis with those of a previous study [32].

\subsection{Restoration of HFS-Induced LTP by Avn-C}

Previous studies have reported synaptic plasticity deficits in a well-characterized Tg2576 amyloid precursor protein (APP) transgenic mouse model, including A $\beta$ deposition and impaired LTP in the hippocampal CA1 region [33]. In order to examine the potential function of Avn-C on A $\beta$-caused synaptic impairment, we used hippocampal LTP analysis, the most studied form of synaptic plasticity. Before recording the LTP, tg2576 mouse hippocampal slices were incubated with extracted Avn-C $(50 \mu \mathrm{M})$ for $2 \mathrm{~h}$. Then, the LTP recordings were conducted at CA 3 to CA1 synapses, and LTP was induced by highfrequency stimulation (HFS; two 100-Hz stimulations at a 30-s interval), and field excitatory postsynaptic potentials (fEPSPs) were recorded for at least $1 \mathrm{~h}$. Assessment of LTP showed that HFS-induced LTP was impaired in non-treated Tg2576 mouse hippocampal slices (120.4 $\pm 2 \%$ of baseline, $n=5$ ). Remarkably, Avn-C application restored LTP impairment in the hippocampus of $\operatorname{Tg} 2576$ mice ( $145 \pm 9 \%$ of baseline, $n=6)$, accompanied by an increased fEPSP compared with that of the control (Figure 5a). These data indicated that Avn-C may exert a protective role on synaptic plasticity deficit in $\mathrm{Tg} 2576$ mice brain, leading to the improvement of neuronal function against $A \beta$ pathogenesis. 
a
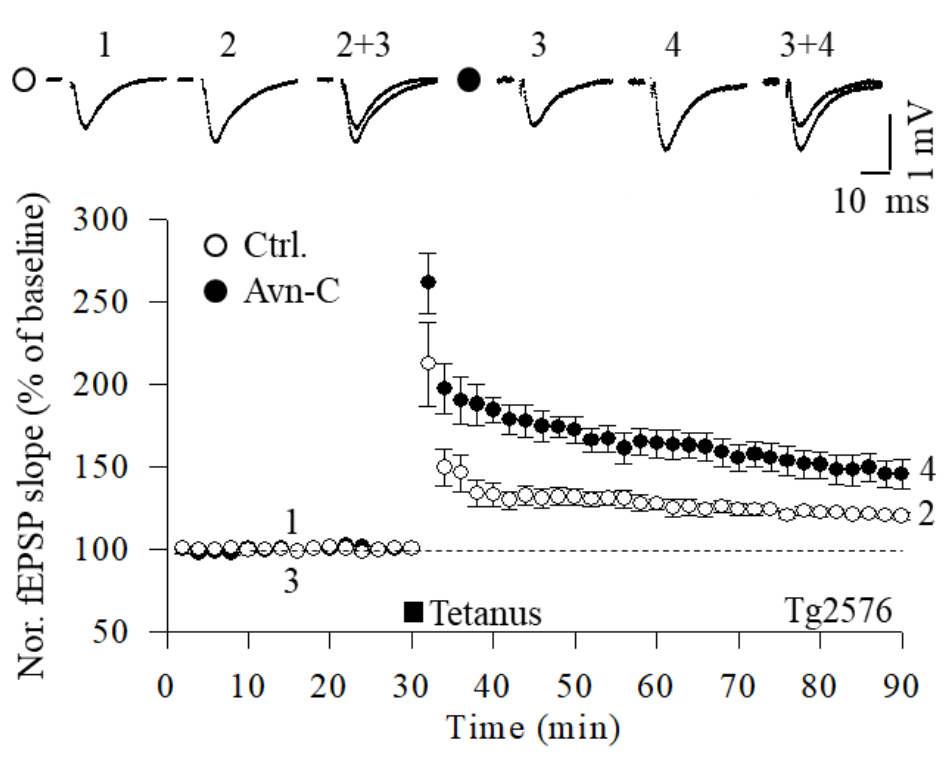

b

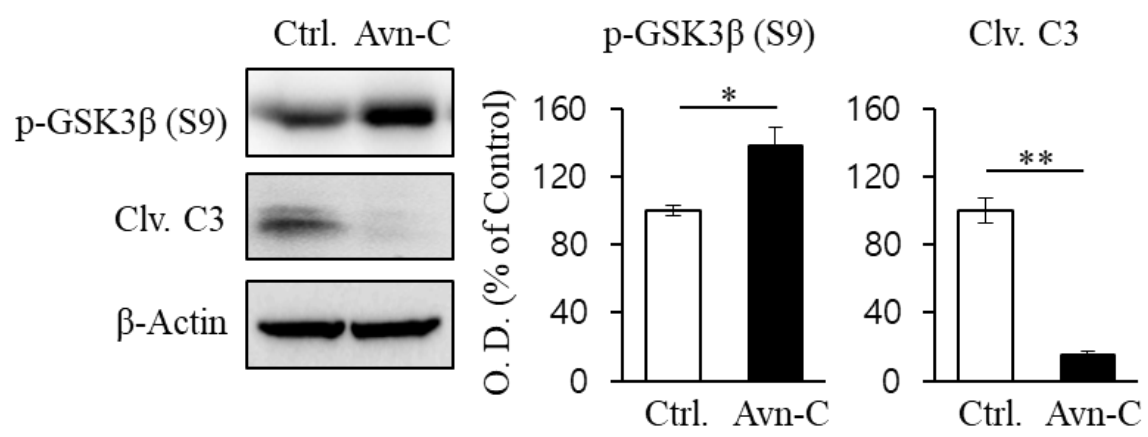

Figure 5. Avn-C restores LTP in Tg2576 mouse hippocampus. (a) LTP induction was triggered by high-frequency stimulation (HFS: $2 \times$ tetanic stimulation at $100 \mathrm{~Hz}, 100$ pulses; interstimulus interval, $30 \mathrm{~s}$ ) in the hippocampal CA1 region of Tg2576 mice. The control group (open circles, $120.4 \pm 2 \%$ of baseline) and Avn-C incubated group (closed circles, $145.9 \pm 9 \%$ of baseline); $n=5$ to 6 per group from 5 to 6 animals. (b) Representative Western blots (left) and group data (right) indicating altered p-GSK3 $\beta$ (S9) and cleaved caspase-3 expression (Clv. C3) in the $50 \mu \mathrm{M}$ Avn-C-treated group compared with that in the control group; $n=4$ per group from 4 animals. Data are expressed as mean \pm S.E.M. Differences were considered significant at ${ }^{*} p<0.05,{ }^{* *} p<0.01$. Ctrl., control; fEPSP, field excitatory postsynaptic potentials; O. D., optical density; Avn-C, Avenanthramide C; LTP, long-term potentiation.

$\mathrm{AD}$ brains contain excessive $\mathrm{A} \beta$ levels linking the hallmarks to synapse damage and disease progression [34]. Even though the accurate mechanisms of $A \beta$ impairs synaptic function are not fully understood, it is believed that acute exposure of hippocampal slices to A $\beta$ inhibits LTP by activating caspase- 3 and GSK3 $\beta$ [35]. To gain further insight into the mechanisms of enhancement of LTP in Avn-C-treated Tg2576 mice, we performed Western blotting experiments on hippocampal slices in the presence of Avn-C. Protein levels of p-GSK3 $\beta$ (S9) were increased and those of cleaved caspase-3 (Clv. C3) were decreased in the Avn-C treated hippocampus (Figure $5 b$ ), suggesting that Avn-C works as an inhibitor to suppress the abnormal activities of GSK3 $\beta$ and caspase- 3 in an AD model mouse brain. This further supports that the mechanism underlies Avn-C rescues $A \beta$-inhibited LTP by modulating GSK3 $\beta$ and caspase- 3 expressions.

It is believed that abnormal activities of caspases and GSK-3 are also highly related to the neuropathology of $\mathrm{AD}[36,37]$. In transgenic AD models, $\mathrm{A} \beta$ activates GSK-3 $\beta$ via inhibiting the phosphorylation of this enzyme [38]. The activation of this enzyme has 
been reported in the postmortem of AD patients [39]. This evidence indicates that the fine-tuning of caspase- 3 and GSK-3 $\beta$ inhibit A $\beta$-induced pathology and LTP impairment under the AD condition. In our finding, Avn-C exerts a protective effect on A $\beta$-induced synapse failure by inhibiting GSK-3 $\beta$. Consistently, GSK-3 $\beta$ inhibition has been shown to reduce $A \beta$ production in AD models [40].

\section{Materials and Methods}

\subsection{General Apparatus and Chemicals}

Column chromatography was performed using Kiselgel 60 (Merck, Art. 7734, Art. 9385, NJ, USA) and RP-18 (YMC, Art. 14878, Japan). All purifications were monitored using thin-layer chromatography (TLC) precoated with Kiselgel 60 F $_{254}$ (Merck, Art. 5715). Compound purifications were performed using a high-performance liquid chromatography (HPLC) core system (Thermo Scientific, Germering, Germany; Dionex Ultimate 3000 Diode Array with ELSD at 254, 280, and 365 nm; and a Dionex Ultimate 3000 pump). A Kinetex $5 \mu \mathrm{m} \mathrm{C18} 100 \AA(250 \times 4.6 \mathrm{~mm}$, Phenomenex, CA, USA) column was used for isolation. The mobile phase consisted of solvent $\mathrm{A}$ (water with $0.1 \%$ acetic acid) and solvent $\mathrm{B}(\mathrm{MeOH}$ with $0.1 \%$ acetic acid) at a flow rate of $1.0 \mathrm{~mL} / \mathrm{min}$. The injection volume was $10 \mu \mathrm{L}$, and the column temperature was $35{ }^{\circ} \mathrm{C}$. The ${ }^{1} \mathrm{H}-\mathrm{NMR}$ spectrum was recorded using a Bruker Avance Digital 500 spectrometer (Karlsruhe, Germany) at $500 \mathrm{MHz}$. Chemical shifts were provided as $\delta$ (ppm) from tetramethylsilane (TMS). All of the reagents were purchased from Sigma-Aldrich (St. Louis, MO, USA).

\subsection{Oat Samples}

Five naked and four covered oat cultivars were used for the analysis of Avns (Table 5). All oats were planted in October and harvested in July between 2014 and 2016 at the National Institute of Crop Science, Rural Development Administration (RDA) Farm, Iksan, Korea. The oats were stored at $14^{\circ} \mathrm{C}$ for 1 month. The naked oats were subjected to a selection process, given the ease of separating the hull from the grain. The outer hull of the covered oats was separated using a short stalk (FC2K, Yamamoto, Japan).

Table 5. Characteristics of the oat cultivars used in this study.

\begin{tabular}{|c|c|c|c|c|c|}
\hline Cultivar & Abbr. & Registration Year & Type & Utilization Type & $\begin{array}{l}\text { Grain Yield } \\
\left(\mathrm{MT} \mathrm{ha}^{-1}\right)\end{array}$ \\
\hline Seonyang & SE & 2003 & Naked & Food & 3.38 \\
\hline Daeyang & DY & 2007 & Naked & Food & 4.18 \\
\hline Choyang & $\mathrm{CY}$ & 2007 & Naked & Food & 4.67 \\
\hline Suyang & SY & 2010 & Naked & Food & 4.35 \\
\hline Jungmo2005 & $\mathrm{JM}$ & 2010 & Naked & Food & 4.35 \\
\hline Samhan & $\mathrm{SH}$ & 2001 & Hulled & Forage use & 4.44 \\
\hline Donghan & $\mathrm{DH}$ & 2001 & Hulled & Forage use & 4.21 \\
\hline Highspeed & HS & 2005 & Hulled & Forage use & 5.00 \\
\hline Jopung & $\mathrm{JP}$ & 2009 & Hulled & Forage use & 5.68 \\
\hline
\end{tabular}

SE, DY, CY, SY, and JM of grain yield were tested at four locations: Gimjae, Iksan, Jeongeup, and Jinju for 3 years. SH and DH grains were tested in Suwon, Unbong, and Iksan. JP was tested in Gimjae in 2014. The HS of grain yield was tested only at the Jeju location. Abbr., abbreviation; MT., Metric Ton.

For germination, the cultivar "Daeyang," which has the high Avn content among Korean oat cultivars, was selected. Oat seeds (500 g) were germinated in plastic dishes with fine holes using the modified soybean germinating utility (temperature of $21^{\circ} \mathrm{C}$, treated with artificial rainfall for $5 \mathrm{~min}$, and stopped for $20 \mathrm{~min}$ ) for $72 \mathrm{~h}$. The oats were collected at 24,48 , and $72 \mathrm{~h}$ and then dried at $40{ }^{\circ} \mathrm{C}$ for $24 \mathrm{~h}$. All of the germinated oat samples were stored at $-70^{\circ} \mathrm{C}$ until laboratory extraction and analysis. All of the samples were ground at $260 \mathrm{~g}$ for $200 \mathrm{~s}$ using an auto-mill disintegrator (Tokken, Japan) in a liquid nitrogen environment. 


\subsection{Sampling of Avns-Rich Fractions}

\subsubsection{Extraction}

Germinated oat flour $(1000 \mathrm{~g})$ was defatted with $4 \mathrm{~L}$ of $\mathrm{n}$-hexane $(500 \mathrm{~mL} \times 2)$ for 7 days at room temperature. The precipitates were placed in a fume hood for $24 \mathrm{~h}$ to completely remove the hexane. Then, $1000 \mathrm{~g}$ of defatted flour was added to $1 \mathrm{~L}$ of $80 \%$ EtOH at $28^{\circ} \mathrm{C}$ for $16 \mathrm{~h}$ in a shaking incubator $(240 \mathrm{rpm})$. Ethanol extract $(80 \%, 500 \mathrm{~g})$ was filtered using Buechner funnels (Duran, Mitterteich, Germany), and the precipitates were re-extracted with $80 \%$ ethanol $(1 \mathrm{~L})$ at $50{ }^{\circ} \mathrm{C}$ for $30 \mathrm{~min}$. The process was repeated twice and then evaporated at $40^{\circ} \mathrm{C}$. The extract $(39.0 \mathrm{~g})$ was suspended in methanol $(200 \mathrm{~mL})$ and was sonicated for $10 \mathrm{~min}$. After centrifugation for $5 \mathrm{~min}$ at $6225 \mathrm{~g}$, the supernatant was evaporated and collected.

\subsubsection{Purification}

Avns-rich fractions from oats were chromatographed on silica gel and RP-18 using a solvent system. The fractions were confirmed to have the same Rf value of Avns using normal-phase TLC. The methanol extract (30.5 g) was chromatographed on silica gel (230-400 mesh, Ø $7.5 \times 35 \mathrm{~cm})$ using a chloroform/methanol/water solvent system under isocratic conditions (10:7:1) to yield 60 fractions (Fr. 1-60) (Figure 1). Each fraction was subjected to normal-phase TLC under the same solvent conditions. Fr. 2 (Fr. 27-36) was confirmed to have the same Rf value as that of Avn-C. The content of Avn-C was analyzed using HPLC.

The subfraction 2-2 (1.03 g) was chromatographed using ODS column $(150 \mu \mathrm{m}$, $\varnothing 2.8 \times 35 \mathrm{~cm}$, stepwise gradient of $40-100 \% \mathrm{MeOH})$ chromatography to yield $30 \mathrm{sub}-$ fractions (SFr. 1-SFr. 30). The subfraction 2-2 (1.03 g) was subjected to HPLC (Luna $5 \mu$, C18, $100 \AA ̊ ㇒ 10 \times 250 \mathrm{~mm}$, Phenomenex, Torrance, CA, 0.1\% HOAc in $40 \% \mathrm{MeOH}, 3.0 \mathrm{~mL}$, $\mathrm{min}^{-1}$ ) system for purification and $2.1 \mathrm{mg}$ of purified compound 1 was obtained from subfraction 16-20.

\subsubsection{Analysis of Avns and $\beta$-Glucan Content}

Finely ground oats $(1 \mathrm{~g})$ were extracted with $100 \mathrm{~mL}$ of $80 \% \mathrm{EtOH}$ in $10 \mathrm{mM}$ phosphate buffer ( $\mathrm{pH} 2.8)$ in a shaking incubator $(240 \mathrm{rpm})$ for $16 \mathrm{~h}$ at $37^{\circ} \mathrm{C}$; this process was repeated three times. The extracts were collected as a filtrate (No. 2) and were evaporated at $50{ }^{\circ} \mathrm{C}$ in a Syncore Analyst (Buchi, Switzerland). Dried samples were resuspended in $2.0 \mathrm{~mL}$ of $80 \% \mathrm{EtOH}$ and filtered through a $0.2-\mu \mathrm{m}$ filter unit (Millipore, Bedford, MA, USA) prior to ultra-performance liquid chromatography (UPLC) analysis.

The UPLC system was equipped with a photodiode array detector (Waters, Milford, MA, USA) with detection at $340 \mathrm{~nm}$ and an Acquity UPLC ${ }^{\circledR}$ HSS C18 column $(2.1 \times 100 \mathrm{~mm}, 1.8 \mu \mathrm{m}$; Waters). The mobile phase comprised buffer A ( $0.01 \mathrm{M}$ phosphate buffer, $\mathrm{pH} 2.8$ ) and buffer B (100\% acetonitrile). A gradient of $15-40 \%$ of buffer B was applied over $9 \mathrm{~min}$ at a flow rate of $0.6 \mathrm{~mL} / \mathrm{min}$. The injection volume was $1 \mu \mathrm{L}$, and the column temperature was adjusted to $35^{\circ} \mathrm{C}$. For quantification and identification purposes, standard stock solutions of Avn-A, Avn-B, and Avn-C were prepared in dimethyl sulfoxide. Avn peaks were identified by comparing the sample retention times with the standards. The concentrations were calculated from the peak areas determined through linear regression. All extracts were obtained from three independent samples.

The $\beta$-glucan content of the oat seeds and extracts was analyzed using an enzyme test kit (Megazyme International Ireland Ltd., Bray Business Park, Bray, Ireland). Briefly, $0.1 \mathrm{~g}$ of sample was mixed with $200 \mu \mathrm{L}$ of $50 \% \mathrm{EtOH}$ and $4 \mathrm{~mL}$ of $20 \mathrm{mM}$ sodium phosphate buffer ( $\mathrm{pH}$ 6.5) by vortexing. The sample was immediately incubated at $100^{\circ} \mathrm{C}$ for $1 \mathrm{~min}$; this process was repeated twice. The extract was incubated at $50{ }^{\circ} \mathrm{C}$ for $5 \mathrm{~min}$ and then mixed with $200 \mu \mathrm{L}$ of lichenase. After $1 \mathrm{~h}$ of reaction and cooling, $5 \mathrm{~mL}$ of $200 \mathrm{mM}$ sodium acetate buffer ( $\mathrm{pH} 4.0$ ) was added to the mixture, followed by centrifugation at $3000 \mathrm{rpm}$ for $10 \mathrm{~min}$. A volume of $100 \mu \mathrm{L}$ of the supernatant was added to $100 \mu \mathrm{L}$ of $\beta$-glucosidase and incubated at $50{ }^{\circ} \mathrm{C}$. 


\subsubsection{Total Phenol Quantification, DPPH, and ABTS}

Total polyphenol quantification was performed with spectrophotometric analysis using the Folin-Ciocalteu phenol reagent. The extract $(100 \mu \mathrm{L})$ was mixed with $2 \% \mathrm{Na}_{2} \mathrm{CO}_{3}$ solution $(2 \mathrm{~mL}$ ) and incubated for $3 \mathrm{~min}$ at room temperature. Then, $100 \mu \mathrm{L}$ of $50 \%$ Folin-Ciocalteu phenol reagent was added. After $3 \mathrm{~min}$ of incubation, the reactants were transferred to a 96-well plate, and the polyphenol content was determined at $750 \mathrm{~nm}$. Gallic acid was used as a standard, and the results were expressed as mg gallic acid equivalent (GAE)/g of extract.

Extracts $(200 \mu \mathrm{L})$ in the cuvette were added to $800 \mu \mathrm{L}$ of DPPH solution $(0.2 \mathrm{mM}$ in ethanol) and incubated for $30 \mathrm{~min}$ at $25^{\circ} \mathrm{C}$ to avoid exposure to light. The antioxidant effects were determined by measuring the absorbance at $515 \mathrm{~nm}$ using a spectrophotometer (Varioskan LUX, Thermo Scientific). To prepare the ABTS stock solution, $7 \mathrm{mM}$ ABTS was mixed with $2.45 \mathrm{mM}$ potassium persulfate and incubated in the dark for $24 \mathrm{~h}$. The stock solution was diluted with methanol to obtain an absorbance between 1.4-1.5 at $735 \mathrm{~nm}$. Diluted ABTS $(1 \mathrm{~mL})$ was added to $50 \mu \mathrm{L}$ of the sample and incubated for $10 \mathrm{~min}$. The absorbance was measured at $735 \mathrm{~nm}$. DPPH radical and ABTS cation radical scavenging activities were expressed in terms of Trolox equivalent (TE) per gram of extract.

\subsection{Animals}

Tg2576 male mice (APP KM670/671NL, Taconic; 9 to 10 months of age) were used for the experiments. The animals were individually housed in ventilated cages with ad libitum access to food and water. The breeding room was controlled with a 12-h light/dark cycle, and the temperature was maintained at $22-30{ }^{\circ} \mathrm{C}$. The animals were sacrificed between 09:00 a.m. and 10:00 a.m. by cervical dislocation. All of the experiments involving animals were performed in accordance with protocols approved by the Institutional Animal Care and Use Committee of Chonnam National University Medical School.

\subsection{Hippocampal Slice Preparation}

After cervical dislocation, the brains were rapidly removed, transferred to ice-cold artificial cerebrospinal fluid (aCSF; $124 \mathrm{mM} \mathrm{NaCl}, 3 \mathrm{mM} \mathrm{KCl}, 26 \mathrm{mM} \mathrm{NaHCO}_{3}, 1.25 \mathrm{mM}$ $\mathrm{NaH}_{2} \mathrm{PO}_{4}, 2 \mathrm{mM} \mathrm{CaCl}, 1 \mathrm{mM} \mathrm{MgSO}$, and $10 \mathrm{mM}$ glucose), and constantly perfused with a gas mixture of $95 \% \mathrm{O}_{2}$ and $5 \% \mathrm{CO}_{2}$. A midsagittal cut was made in the brains and one hemisphere was kept in ice-cold aCSF until it was required. Hippocampal slices were cut transversely (400- $\mu \mathrm{m}$ thick) using a Mcllwain tissue chopper (Mickle Laboratory Engineering Co. Ltd., Surrey, UK) and were stabilized for $1 \mathrm{~h}$ in aCSF at room temperature.

\subsection{Electrophysiology}

Hippocampal slices were treated with $50 \mu \mathrm{M}$ Avn-C for $2 \mathrm{~h}$ prior to recordings. Stimulating electrodes were placed in the Schaffer collateral pathway. Extracellular field potentials were recorded in the CA1 region using microcapillary electrodes containing $3 \mathrm{M} \mathrm{NaCl}$. Stimuli were delivered alternately to the two electrodes $(0.016 \mathrm{~Hz}$ for each electrode). After establishing a stable baseline for $30 \mathrm{~min}$, LTP was induced by high-frequency stimulation (HFS; two 100-Hz stimulations for $1 \mathrm{~s}$ at a 30-s interval), and field excitatory postsynaptic potentials (fEPSPs) were recorded for at least $1 \mathrm{~h}$. The slope of the evoked field potential response was measured and expressed relative to the normalized baseline. Data were collected using an NI USB-6251 data acquisition module (National Instruments, Austin, Texas, USA), amplified by an Axopatch 700 B amplifier (Axon Instruments, Foster City, CA, USA), and captured and analyzed using WinLTP 2.32 software (www.winltp.com, accseed on 6 September 2021).

\subsection{Immunoblotting}

Hippocampal tissue lysates were prepared using a radioimmunoprecipitation assay buffer (Cell Biolabs, Inc., San Diego, CA, USA). Protein concentrations were determined using a bicinchoninic acid (BCA) assay. The proteins were separated on $10-12 \%$ gels and 
transferred to polyvinylidene fluoride (PVDF) membranes (Millipore, Bedford, MA, USA), which were incubated overnight with primary antibodies. The following primary antibodies were purchased from Cell Signaling Technology (MA, USA): anti-cleaved caspase-3 (1:1000), anti-phospho-GSK-3 $\beta$ (Ser9) (p-GSK3 $\beta$-S9) (1:1000), and anti- $\beta$-actin (1:1000). Membranes were then incubated with rabbit IgG antibodies (1:3000, Cell Signaling Technology) conjugated to horseradish peroxidase and immunoblotted using an enhanced chemiluminescence (ECL) detection system (Millipore, Bedford, MA, USA). The optical density of the immunoreactive bands was measured using ImageJ software (National Institutes of Health, Bethesda, MD, USA).

\subsection{Statistical Analysis}

All experiments were performed in triplicate. The data are expressed as the mean \pm standard error of the mean (S.E.M.). Statistical significance was determined using one-way ANOVA. Statistical analyses were performed using GraphPad Prism 7 (GraphPad, La Jolla, CA, USA) and SAS version 9.2 (SAS Institute, Cary, NC, USA). Means were compared using Duncan's test or an unpaired Student's $t$-test. Statistical significance was set at $p<0.05$.

\section{Conclusions}

Alzheimer's disease is a neurodegenerative disorder and is the most prevalent form of dementia all over the world. AD attacks the central nervous system and leads to synapses loss, cognitive deficit, and memory decline. It is associated with pathological accumulation of $\mathrm{A} \beta$ plaques in the brain. The increasing number of $\mathrm{AD}$ incidence require new therapeutic agents [41]. Among them, natural compounds have recently been paid attention and their potential effects on $\mathrm{AD}$ pathology have been well documented, for example, vitamin $C$ reduces $A \beta$ plaques in an AD mouse model [42], Bryostatin extracted from bryozoan Bugula neritina inhibits the $A \beta$ accumulation and enhances memory function in AD mouse model [43], and Resveratrol is a natural compound present in grapes that exerts clearance effect on $A \beta$ aggregates [44]. This study demonstrated for the first time that Avn-C, extracted from germinated oats, prevented the impairment of synaptic plasticity in Tg2576 mice and abnormal activation of GSK3 $\beta$ under AD pathologies. Our findings suggest Avn-C as a potential therapeutic candidate for AD-related synaptic plasticity impairment and memory decline. Nevertheless, we cannot disregard other factors that also involve in AD progression, such as the known hyperphosphorylated tau protein and the neuroinflammation in the central nervous system [45]. Accumulation of p-tau protein in the neurofibrillary tangles accompanied by an increase of GSK3 $\beta$ activity [46] directed us to consider the potential role of Avn-C on tau pathology. Additionally, the anti-inflammatory benefits [47] of Avn-C have been reported [25], therefore, the anti-neuroinflammation effect of Avn-C in AD remains to be further evaluated.

Author Contributions: Conceptualization, Y.-Y.L., M.-S.K., H.-S.K., and J.J.; methodology, H.-S.K., J.J., and Y.-Y.L. investigation, Y.S., E.-J.Y., H.-J.K., and M.W.; writing-original draft preparation, Y.-Y.L.; writing—review and editing, M.W., J.J., and Y.-Y.L.; project administration, Y.-Y.L. and J.J.; funding acquisition, Y.-Y.L. All authors have read and agreed to the published version of the manuscript.

Funding: This research was funded by the Cooperative Research Program for Agriculture Science \& Technology Development (PJ01255102 and PJ01255104), BioGreen21 Agri-Tech Innovation Program (PJ01561601), the Rural Development Administration, the Republic of Korea, the Commercializations Promotion Agency for R\&D Outcomes (COMPA) grant funded by the Korea government (MSIT) (No. 2021C100) and NRF-2021R111A2048344.

Institutional Review Board Statement: All experiments involving animals were performed in accordance with the protocols approved by the Institutional Animal Care and Use Committee of Chonnam National University Medical School.

Informed Consent Statement: Not applicable. 
Data Availability Statement: The data presented in this study are available upon request from the corresponding author.

Conflicts of Interest: The authors declare no financial conflicts of interest.

Sample Availability: Samples of the compounds are available from the authors.

\section{References}

1. Palop, J.J.; Mucke, L. Amyloid-beta-induced neuronal dysfunction in Alzheimer's disease: From synapses toward neural networks. Nat. Neurosci. 2010, 13, 812-818. [CrossRef]

2. Shankar, G.M.; Walsh, D.M. Alzheimer's disease: Synaptic dysfunction and A $\beta$. Mol. Neurodegener. 2009, 4, 48. [CrossRef] [PubMed]

3. Lambert, M.P.; Barlow, A.K.; Chromy, B.A.; Edwards, C.; Freed, R.; Liosatos, M.; Morgan, T.E.; Rozovsky, I.; Trommer, B.; Viola, K.L.; et al. Diffusible, nonfibrillar ligands derived from Ab1-42 are potent central nervous system neurotoxins. Proc. Natl. Acad. Sci. USA 1998, 95, 6448-6453. [CrossRef] [PubMed]

4. Martin, L.J.; Pardo, C.A.; Cork, L.C.; Price, D.L. Synaptic pathology and glial responses to neuronal injury precede the formation of senile plaques and amyloid deposits in the aging cerebral cortex. Am. J. Pathol. 1994, 145, 1358-1381. [PubMed]

5. Lynch, M.A. Long-term potentiation and memory. Physiol. Rev. 2004, 84, 87-136. [CrossRef]

6. Whitlock, J.R.; Heynen, A.J.; Shuler, M.G.; Bear, M.F. Learning induces long-term potentiation in the hippocampus. Science 2006, 313, 1093-1097. [CrossRef]

7. Hwang, K.D.; Bak, M.S.; Kim, S.J.; Rhee, S.; Lee, Y.S. Restoring synaptic plasticity and memory in mouse models of Alzheimer's disease by PKR inhibition. Mol. Brain 2017, 10, 57. [CrossRef]

8. Prieto, G.A.; Trieu, B.H.; Dang, C.T.; Bilousova, T.; Gylys, K.H.; Berchtold, N.C.; Lynch, G.; Cotman, C.W. Pharmacological rescue of long-term potentiation in Alzheimer disease-related synapses. J. Neurosci. 2017, 37, 1197-1212. [CrossRef]

9. Wang, M.; Yoon, G.; Song, J.; Jo, J. Exendin-4 improves long-term potentiation and neuronal dendritic growth under in vivo and in vitro obesity condition. Sci. Rep. 2021, 11, 8326. [CrossRef]

10. Canady, V.A. FDA Approves First Drug Therapy for Alzheimer's in 18 Years. Ment. Health Wkly. 2021, 31, 3-4. [CrossRef]

11. Ciccone, L.; Vandooren, J.; Nencetti, S.; Orlandini, E. Natural Marine and Terrestrial Compounds as Modulators of Matrix Metalloproteinases-2 (MMP-2) and MMP-9 in Alzheimer's Disease. Pharmaceuticals 2021, 14, 86. [CrossRef] [PubMed]

12. Ferreira, J.P.S.; Albuquerque, H.M.T.; Cardoso, S.M.; Silva, A.M.S.; Silva, V.L.M. Dual-target compounds for Alzheimer's disease: Natural and synthetic AChE and BACE-1 dual-inhibitors and their structure-activity relationship (SAR). Eur. J. Med. Chem. 2021, 221, 113492. [CrossRef] [PubMed]

13. Martins, M.; Silva, R.; Pinto, M.M.M.; Sousa, E. Marine Natural Products, Multitarget Therapy and Repurposed Agents in Alzheimer's Disease. Pharmaceuticals 2020, 13, 242. [CrossRef] [PubMed]

14. Peterson, D.M. Composition and nutritional characteristics of oat grains and products. Oat Sci. Technol. 1992, 33, $265-292$.

15. Welch, R.W. Oat, Human Nutrition and Health. In The Oat Crop, 1st ed.; Welch, R.W., Ed.; Springer: Dordrecht, The Netherlands, 1995; pp. 433-479.

16. Tapola, N.; Karvonen, H.; Niskanen, L.; Mikola, M.; Sarkkinen, E. Glycemic responses of oat bran products in type 2 diabetic patients. Nutr. Metab. Cardiovasc. Dis. 2000, 15, 255-261. [CrossRef] [PubMed]

17. Zduńczyk, Z.; Flis, M.; Zieliński, H.; Wróblewska, M.; Antoszkiewicz, Z.; Juśkiewicz, J. In vitro antioxidant activities of barley, husked oat, naked oat, triticale, and buckwheat wastes and their influence on the growth and biomarkers of antioxidant status in rats. J. Agric. Food Chem. 2006, 54, 4168-4175. [CrossRef]

18. Boz, H. Phenolic amides (Avenanthramides) in oats: A review. Czech J. Food Sci. 2015, 33, 399-404. [CrossRef]

19. Emmons, C.L.; Peterson, D.M. Antioxidant activity and phenolic contents of oat groats and hulls. Cereal Chem. 1999, 76, 902-906. [CrossRef]

20. Dimberg, L.H.; Theander, O.; Lingnert, H. Avenanthramides-A group of phenolic antioxidants in oats. Cereal Chem. 1993, 70, 637-641.

21. Meydani, M. Potential health benefits of avenanthramides of oats. Nutr. Rev. 2009, 67, 731-735. [CrossRef]

22. Verardo, V.; Serea, C.; Segal, R.; Caboni, M.F. Free and bound minor polar compounds in oats: Different extraction methods and analytical determinations. J. Cereal Sci. 2011, 54, 211-217. [CrossRef]

23. Yang, J.; Ou, B.; Wise, M.L.; Chu, Y. In vitro total antioxidant capacity and anti-inflammatory activity of three common oat-derived avenanthramides. Food Chem. 2014, 160, 338-345. [CrossRef] [PubMed]

24. Guo, W.; Wise, M.L.; Collins, F.W.; Meydani, M. Avenanthramides, polyphenols from oats, inhibit IL-1beta-induced NF-kappaB activation in endothelial cells. Free Radic. Biol. Med. 2008, 44, 415-429. [CrossRef] [PubMed]

25. Sur, R.; Nigam, A.; Grote, D.; Liebel, F.; Southall, M.D. Avenanthramides, polyphenols from oats, exhibit anti-inflammatory and anti-itch activity. Arch. Dermatol. Res. 2008, 300, 569-574. [CrossRef] [PubMed]

26. Chen, C.Y.O.; Milbury, P.E.; Collins, F.W.; Blumberg, J.B. Avenanthramides are bioavailable and have antioxidant activity in humans after acute consumption of an enriched mixture from oats. J. Nutr. 2007, 137, 1375-1382. [CrossRef] [PubMed]

27. Peterson, D.M.; Hahn, M.J.; Emmons, C.L. Oat avenanthramides exhibit antioxidant activities in vitro. Food Chem. 2002, 79, 473-478. [CrossRef] 
28. Ramasamy, V.S.; Samidurai, M.; Park, H.J.; Wang, M.; Park, R.Y.; Yu, S.Y.; Kang, H.K.; Hong, S.; Choi, W.S.; Lee, Y.Y.; et al. Avenanthramide-C restores impaired plasticity and cognition in Alzheimer's disease model mice. Mol. Neurobiol. 2020, 57, 315-330. [CrossRef]

29. Rasane, P.; Jha, A.; Sabikhi, L.; Kumar, A.; Unnikrishnan, V.S. Nutritional advantages of oats and opportunities for its processing as value added foods-A review. J. Food Sci. Technol. 2015, 52, 662-675. [CrossRef]

30. Emmons, C.; Peterson, D.M. Antioxidant activity and phenolic content of oat as affected by cultivar and location. Crop Sci. 2001, 41,1676-1681. [CrossRef]

31. Skoglund, M.; Peterson, D.M.; Andersson, R.; Nilsson, J.; Dimberg, L.H. Avenanthramide content and related enzyme activities in oats are affected by steeping and germination. J. Cereal Sci. 2008, 48, 294-303. [CrossRef]

32. Wise, M.L. Effect of chemical systemic acquired resistance elicitors on avenanthramide biosynthesis in oat (Avena sativa). J. Agric. Food Chem. 2011, 59, 7028-7038. [CrossRef] [PubMed]

33. Lesné, S.; Koh, M.T.; Kotilinek, L.; Kayed, R.; Glabe, C.G.; Yang, A.; Gallagher, M.; Ashe, K.H. A specific amyloid- $\beta$ protein assembly in the brain impairs memory. Nature 2006, 440, 352-357. [CrossRef]

34. Ferreira, S.T.; Lourenco, M.V.; Oliveira, M.M.; Felice, F.G.D. Soluble amyloid- $\beta$ oligomers as synaptotoxins leading to cognitive impairment in Alzheimer's disease. Front. Cell. Neurosci. 2015, 9, 191. [CrossRef]

35. Jo, J.; Whitcomb, D.J.; Olsen, K.M.; Kerrigan, T.L.; Lo, S.C.; Bru-Mercier, G.; Dickinson, B.; Scullion, S.; Sheng, M.; Collingridge, G.; et al. A $\beta$ (1-42) inhibition of LTP is mediated by a signaling pathway involving caspase-3, Akt1 and GSK-3ß. Nat. Neurosci. 2011, 14, 545-547. [CrossRef]

36. Llorens-Martín, M.; Jurado, J.; Hernández, F.; Ávila, J. GSK-3ß, a pivotal kinase in Alzheimer disease. Front. Mol. Neurosci. 2014, 7, 1-11. [CrossRef]

37. D'Amelio, M.; Cavallucci, V.; Cecconi, F. Neuronal caspase-3 signaling: Not only cell death. Cell Death Differ. 2010, 17, 1104-1114 [CrossRef] [PubMed]

38. Takashima, A.; Noguchi, K.; Michel, G.; Mercken, M.; Hoshi, M.; Ishiguro, K.; Imahori, K. Exposure of rat hippocampal neurons to amyloid $\beta$ peptide (25-35) induces the inactivation of phosphatidyl inositol-3 kinase and the activation of tau protein kinase I/glycogen synthase kinase-3ß. Neurosci. Lett. 1996, 203, 33-36. [CrossRef]

39. Leroy, K.; Yilmaz, Z.; Brion, J.-P. Increased level of active GSK-3 $\beta$ in Alzheimer's disease and accumulation in argyrophilic grains and in neurones at different stages of neurofibrillary degeneration. Neuropathol. Appl. Neurobiol. 2007, 33, 43-55. [CrossRef]

40. Phiel, C.J.; Wilson, C.A.; Lee, V.M.-Y.; Klein, P.S. GSK-3 $\alpha$ regulates production of Alzheimer's disease amyloid- $\beta$ peptides. Nature 2003, 423, 435-439. [CrossRef] [PubMed]

41. Folch, J.; Petrov, D.; Ettcheto, M.; Abad, S.; Sánchez-López, E.; García, M.L.; Olloquequi, J.; Beas-Zarate, C.; Auladell, C.; Camins, A. Current Research Therapeutic Strategies for Alzheimer's Disease Treatment. Neural Plasticity 2016, 2016, 8501693. [CrossRef]

42. Murakami, K.; Murata, N.; Ozawa, Y.; Kinoshita, N.; Irie, K.; Shirasawa, T.; Shimizu, T. Vitamin C Restores Behavioral Deficits and Amyloid- $\beta$ Oligomerization without Affecting Plaque Formation in a Mouse Model of Alzheimer's Disease. J. Alzheimer's Dis. 2011, 26, 7-18. [CrossRef] [PubMed]

43. Schrott, L.M.; Jackson, K.; Yi, P.; Dietz, F.; Johnson, G.S.; Basting, T.F.; Purdum, G.; Tyler, T.; Rios, J.D.; Castor, T.P.; et al. Acute Oral Bryostatin-1 Administration Improves Learning Deficits in the APP/PS1 Transgenic Mouse Model of Alzheimer's Disease. Curr. Alzheimer Res. 2015, 12, 22-31. [CrossRef]

44. Marambaud, P.; Zhao, H.; Davies, P. Resveratrol Promotes Clearance of Alzheimer's Disease Amyloid- $\beta$ Peptides. J. Biol. Chem. 2005, 280, 37377-37382. [CrossRef]

45. Iqbal, K.; Alonso, A.D.; Chen, S.; Chohan, M.O.; El-Akkad, E.; Gong, C.X.; Khatoon, S.; Li, B.; Liu, F.; Rahman, A.; et al. Tau pathology in Alzheimer disease and other tauopathies. Biochim. Biophys. Acta (BBA)-Mol. Basis Dis. 2005, 1739, 198-210. [CrossRef]

46. Heneka, M.T.; Carson, M.J.; El Khoury, J.; Landreth, G.E.; Brosseron, F.; Feinstein, D.L.; Jacobs, A.H.; Wyss-Coray, T.; Vitorica, J.; Ransohoff, R.M.; et al. Neuroinflammation in Alzheimer's disease. Lancet Neurol. 2015, 14, 388-405. [CrossRef]

47. Toral-Rios, D.; Pichardo-Rojas, P.S.; Alonso-Vanegas, M.; Campos-Peña, V. GSK3 $\beta$ and Tau Protein in Alzheimer's Disease and Epilepsy. Front. Cell. Neurosci. 2020, 14, 19. [CrossRef] [PubMed] 